\title{
Catalytic Oxygen Transfer Between Propylene and Propylene Oxide
}

\author{
G. MANARA* AND G. PARRAVANO \\ Department of Chemical Engineering, University of Michigan, \\ Ann Arbor, Michigan 48104
}

Received June 13, 1973

\begin{abstract}
The transfer of oxygen between propylene and propylene oxide has been studied at surfaces of silver, gold and $\left(\mathrm{VO}_{2}\right)_{x}$. The study was carried out by following the rate of isotopic carbon distribution between propylene and propylene oxide. The following conditions were employed in the experiments: temperature, 60 to $270^{\circ} \mathrm{C}$; partial pressure ratio propylene oxide to propylene, 0.35 to 30 ; contact time, 1 to 10 sec. No homogeneous reaction nor catalytic decompositions were detected. $\mathrm{CO}_{2}$ formation was $<3 \%$. Silver was supported on high and low area $\mathrm{Al}_{2} \mathrm{O}_{3}$ or complexed with poly(4-vinylpyridine); gold was supported on $\mathrm{MgO}$. The influence of the ratio of the partial pressures of propylene oxide to propylene on the reaction rate was quantitatively measured on each catalyst and taken as an indication of processes of competitive reactive chemisorption of propylene and propylene oxide. The analysis showed that on silver supported on low area $\mathrm{Al}_{2} \mathrm{O}_{3}$, single site adsorption was predominant, while two site adsorption prevailed at the surfaces of the other catalysts tested. Some amount of mixed behavior occurred on all catalysts. Kinetically, the carbon isotope exchange reaction was analyzed in terms of sequcnce of adsorptiondesorption steps. By combining the rate of these steps with that of similar steps for ethylene and ethylene oxide it was possible to predict conditions for the epoxidation of propylene by means of ethylene oxide. A semiquantitative confirmation of this prediction gave supporting evidence for the internal consistence of the kinetic model discussed.
\end{abstract}

In a recent study (1) on the reactive adsorption of mixtures of ethylene (ET) and ethylene oxide (ETO) at surfaces of oxidation catalysts two adsorption modes of ethylene were deduced and their role in catalyst reactivity in the oxidation of $\mathrm{ET}$ to ETO and $\mathrm{CO}_{2}$ was brought to light. The basis of the investigation and of the analysis was the derivation of the reactive adsorption isotherm of ET. Since this approach permits a classification of reactive ethylene adsorption, which may be further related to structural, kinetic and selectivity factors, it seemed of interest to extend the method to a study of the reactive adsorption of mixtures of propylene (PR)

* Permanent address: SNAM Progetti S.p.A., I-39030, San Donato Milanese, Italy.

Copyright (C) 1974 by Academic Press, Inc.

All rights of reproduction in any form reserved. and propylene oxide (PRO). The problem of the selectivity to PRO in PR oxidation, i.e., the relative role of parallel versus consecutive pathways, is still unresolved. Some reports (2) ascribe the low yield in PRO over $\mathrm{Ag}$ to a low rate of formation of the epoxide, while others (3) indicate a very high combustion rate of the epoxide over silver under the conditions of its formation from $P R$ and oxygen. Although direct results on the selectivity to PRO with our catalysts are not available, it seemed that a comparison between the reactive adsorption of ethylene and that of propylene in the presence of their corresponding epoxides and in the absence of molecular oxygen may contribute further to the understanding of the catalytic pathways of olefin oxidation reactions. 
In the case of ethylene, the interaction between the olefin molecule and the catalyst surface may be visualized as single site adsorption which retains some double bond character in the olefin molecule ( $\pi$ bond interaction), and two site adsorption ( $\alpha$-bond interaction) which leads to the possibility of $\mathrm{C}-\mathrm{C}$ bond fission. It may, then, be asked whether the adsorption pattern, determined for a given set of catalytic surfaces for ethylene, is modified in the instance of an olefin possessing the additional adsorption possibility of allylic hydrogen attack (4). From the point of view of the simple scheme of adsorption employed here one may expect that adsorption followed by allylic attack require two surface sites, at least initially; it is clear, however, that a distinction between the latter type of adsorption and that involving $\sigma$-bond interaction cannot be made without direct measurements on the products of the net oxidation reastion.

The reactive adsorption of mixtures of $P R$ and PRO was investigated by measuring the rate of the catalytic carbon isotope redistribution reaction:

${ }^{*} \mathrm{C}_{3} \mathrm{H}_{6}(\mathrm{~g})+\mathrm{C}_{3} \mathrm{H}_{6} \mathrm{O}(\mathrm{g}) \rightarrow \mathrm{C}_{3} \mathrm{H}_{6}(\mathrm{~g})+{ }^{*} \mathrm{C}_{3} \mathrm{H}_{6} \mathrm{O}(\mathrm{g}),(\mathrm{I})$

where ${ }^{\mathrm{C}}$ is a carbon-14 atom and $(\mathrm{g})$ refers to gas phase. In the absence of side products, the rate of reaction (1) is equal to the rate of PR adsorption on an oxygenated surface leading to PRO. 'This may be formally represented by

$$
\begin{aligned}
{ }^{*} \mathrm{C}_{3} \mathrm{H}_{6}(\mathrm{~g})+\mathrm{O}(\mathrm{s}) & \rightarrow{ }^{*} \mathrm{C}_{3} \mathrm{H}_{6} \mathrm{O}(\mathrm{g}), \\
\mathrm{C}_{3} \mathrm{H}_{6} \mathrm{O}(\mathrm{g}) & \rightarrow \mathrm{C}_{3} \mathrm{H}_{6}(\mathrm{~g})+\mathrm{O}(\mathrm{s}),
\end{aligned}
$$

where $(\mathrm{s})$ refers to the adsorbed phase. Reactions (1a) and (1b) comprise the kinetic sequence of adsorption and desorption steps, which lead to reaction (1). Since the latter is an equilibrium reaction, its rate and that of reaction steps (1a) and (1b) are similar. Thus, rate measurements on reaction (1) yield directly the rate of reaction step (1a) [or (1b)].

In order to test some of the conclusions derived from the study of reaction (1), the catalytic epoxidation of $\mathrm{PR}$ by means of ETO:
$\mathrm{C}_{2} \mathrm{H}_{4} \mathrm{O}(\mathrm{g})+\mathrm{C}_{3} \mathrm{H}_{6}(\mathrm{~g}) \rightarrow \mathrm{C}_{2} \mathrm{H}_{4}(\mathrm{~g})+\mathrm{C}_{3} \mathrm{H}_{6} \mathrm{O}(\mathrm{g})$

was investigated in a few runs. In this communication we summarize the results collected in the study of the rates of reactions (1) and (2).

\section{Malerials}

High purity compressed gases were used without further purification. One millicurie of carbon-14 labeled PR was mixed with nonradioactive $\mathrm{PR}(>99.5 \%)$ and stored in a cylinder under pressure. The carrier gas was high purity A $(>99.995 \%)$. Three supported Ag catalysts were studied. A detailed description of their preparation has already been reported (1). Briefly $\mathrm{Ag}-1$ was prepared by reacting at room temperature solutions of $\mathrm{AgNO}_{3}$ and $\mathrm{Na}_{2} \mathrm{CO}_{3}$, adding to the dried precipitate of $\mathrm{Ag}_{2} \mathrm{CO}_{3}$ lactic acid $\left(85 \% \mathrm{H}_{2} \mathrm{O}\right.$ solution) at $90^{\circ} \mathrm{C}$. $\mathrm{H}_{2} \mathrm{O}_{2}(30 \%)$ was then added, followed by solutions of $\mathrm{Ca}$ and $\mathrm{Ba}$ lactates. Support impregnation $\left(\alpha-\right.$ and $\left.\gamma-\mathrm{Al}_{2} \mathrm{O}_{3}\right)$ was carried out at $90^{\circ} \mathrm{C}$. The catalyst, dried over night under a stream of air, was calcined at $315^{\circ} \mathrm{C}$ for $5 \mathrm{hr}$ in air. Ag-3 was prepared in a similar manner but contained $\mathrm{Ba}$ lactate only. Ag-5 was prepared by adding a solution of $\mathrm{AgNO}_{3}$ in $\mathrm{CH}_{3} \mathrm{OH}+\mathrm{H}_{2} \mathrm{O}$ to a solution of poly(4-vinylpyridine) in $\mathrm{CH}_{3} \mathrm{OH}$. The precipitate was filtered, dried under vacuum and used without further purification. Ag analysis of the catalysts were carried out aecording to the Volhard method. Ag surface areas were measured by $\mathrm{O}_{2}$ adsorption, $\mathrm{X}$-ray diffraction (in the range $50800 \AA$ ) and electron microscopy.

Two supported Au catalysts were tested. They were prepared by impregnation of reagent grade $\mathrm{MgO}\left(18 \mathrm{~m}^{2} / \mathrm{g}\right.$ surface area) with solution of $\mathrm{HAluCl}_{4} \cdot 3 \mathrm{H}_{2} \mathrm{O}$. The slurry was air dried and heat treated at $350^{\circ} \mathrm{C}$ for $2 \mathrm{hr}$ at 0.1 Torr (Au-1) or treated at $100^{\circ} \mathrm{C}$ with a $3 \%$ solution of oxalic acid and subsequently dried and heat treated in a similar fashion (Au-2). More details on the preparation and characterization of the Au catalysts may be found elsewhere (5). Typical properties $\mathrm{Ag}$ and $\mathrm{Au}$ catalysts are summarized in Table 1. A few runs were also performed employing a com- 
TABLE 1

Porosity, Surface Area and Composition of Supported Ag and Au Catalysts

\begin{tabular}{|c|c|c|c|c|c|c|c|}
\hline \multirow[b]{2}{*}{ Catalyst } & \multicolumn{3}{|c|}{ Support } & \multicolumn{2}{|c|}{ Composition } & \multicolumn{2}{|c|}{ Metal } \\
\hline & Type & $\begin{array}{l}\text { Porosity } \\
\left(\mathrm{cm}^{3} / \mathrm{g}\right)\end{array}$ & $\begin{array}{c}\text { Av pore } \\
\text { diam } \\
(\AA)\end{array}$ & $\begin{array}{l}\text { Metal } \\
(\mathrm{wt} \%)\end{array}$ & $\begin{array}{c}\text { Additions } \\
\text { (molar ratio) }\end{array}$ & $\begin{array}{c}\text { Surface } \\
\text { area } \\
\left(\mathrm{m}^{2} / \mathrm{g}\right)\end{array}$ & $\begin{array}{c}\text { Crystallite } \\
\text { size } \\
(\AA)\end{array}$ \\
\hline $\mathrm{Ag}-1$ & $\alpha-\mathrm{Al}_{2} \mathrm{O}_{3}$ & 0.31 & 5000 & 15.3 & $\begin{array}{c}\mathrm{Ag}: \mathrm{Ba}: \mathrm{Ca}= \\
1400: 7: 0.25\end{array}$ & 11.3 & 500 \\
\hline $\mathrm{Ag}-3$ & $\gamma-\mathrm{Al}_{2} \mathrm{O}_{3}$ & 0.80 & 250 & 21.3 & $\begin{array}{c}\mathrm{Ag}: \mathrm{Ba}= \\
1400: 7\end{array}$ & 50 & 100 \\
\hline $\mathrm{Ag}-5$ & \multicolumn{3}{|c|}{ Ag-poly (4 vinylpyridine) complex } & 23.8 & - & - & $30-40$ \\
\hline Au-1\} & \multirow{2}{*}{$\mathrm{MgO}$} & \multirow{2}{*}{\multicolumn{2}{|c|}{$\begin{array}{l}\text { Surface area } \\
18 \mathrm{~m}^{2} / \mathrm{g}\end{array}$}} & 0.7 & - & 0.0165 & 1321 \\
\hline $\mathrm{Au}-2\}$ & & & & 2 & 一 & 1.24 & 50 \\
\hline
\end{tabular}

mercial preparation of $\left(\mathrm{VO}_{2}\right)_{x}$ as catalyst $\left(16 \mathrm{~m}^{2} / \mathrm{g}\right.$ surface area). The catalysts were ground and sieved, the fraction between 30 to 45 mesh was utilized. Reaction conditions were stabilized during a $6 \mathrm{hr}$ period, prior to the kinetic measurements.

\section{Equipment}

The rate of reaction (1) was studied in a flow system at atmospheric pressure. Metered streams of $\mathrm{A},{ }^{*} \mathrm{PR}$ and $\mathrm{PR}$ were dried over $\mathrm{MgClO}_{4}$ and led into a tubular glass reactor. Additional streams of A were flowed into a $\mathrm{PRO}$ saturator maintained at low temperature $\left(-30\right.$ to $\left.20^{\circ} \mathrm{C}\right)$. Gas analysis was performed by gas chromatography. The column employed was filled with Porapak Q and permitted easy separation of $\mathrm{PR}, \mathrm{PRO}$ at a temperature of 150 to $180^{\circ} \mathrm{C}$. The fractions eluting from the chromatograph were collected in a solution of PPO-2,5-diphenyloxazole in toluene for liquid scintillation analysis.

Reaction (2) was studied in a flow reactor. Separate gas mixtures $\mathrm{N}_{2}+$ ETO and $\mathrm{N}_{2}+\mathrm{PR}$ were prepared and stored in pressurized cylinders. A space velocity of $0.21\left[\mathrm{~cm}^{3} \times \mathrm{min} / \mathrm{g}\right.$ (cat) $]$ was employed for mixture of $\mathrm{N}_{2}+\mathrm{ETO}+\mathrm{PR}$. Analysis was performed by temperature programmed gas chromatography. No formation of PRO was detected at temperatures $<200^{\circ} \mathrm{C}$. Carbon balances were generally $>97 \%$. The formation of a small amount of $\mathrm{CO}_{2}$ $(<1 \%)$ was detected at the highest temperature.

\section{Procedure}

Before each measurement of composition and radioactivity on the exit stream of the reactor in the case of reaction (1), a sample of the inlet stream was collected and analyzed. The radioactive count of the PRO fraction in the inlet stream was used as the background count. Counting cycles from 10 to $150 \mathrm{~min}$ were used, and the corresponding statistical error was $2 \%$ for PRO and $1 \%$ for PR. The presence or absence of $\mathrm{CO}_{2}$ in the effluent gas, was determined by collecting the effluent in a solution of $\mathrm{Ba}(\mathrm{OH})_{2}$ and titrating it. The operating conditions chosen for the study of each catalyst were such that in every case $<\mathbf{3} \%$ of $\mathrm{CO}_{2}$ was produced. Reaction conversions up to about $15 \%$ were measured. The experimental error in the values of the parameters $k$ and $m$ (see below) were estimated at 30 and $5 \%$, respectively.

\section{Experimental Results}

\section{Reaction (1)}

The temperature range in which reaction (1) could be studied without concomitant side reactions varied greatly depending upon the catalyst employed. On supported $\mathrm{Ag}$, the range was between 60 and $186^{\circ} \mathrm{C}$, while on $\mathrm{Au}$ preparations temperatures of 215 to $270^{\circ} \mathrm{C}$ were needed. Even at the higher temperatures, however, no appreciable decomposition or dehydrogenation of PRO took place, nor there was evidence 


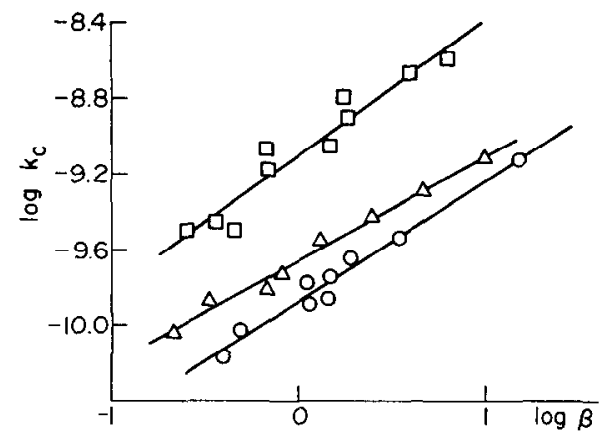

FIG. 1. Values of $\log k_{c}$ [Eq. (4)] versus $\log \beta$ for reaction (1): (○) $\mathrm{Ag}-1\left(186^{\circ} \mathrm{C}\right) ;(\triangle) \mathrm{Ag}-3$ $\left(90^{\circ} \mathrm{C}\right),(\square) \mathrm{Ag}-5\left(60^{\circ} \mathrm{C}\right)$.

of occurrence of the homogeneous reaction. The rate of reaction (1) is given by:

$$
\frac{1}{W} \frac{d p_{* \mathrm{PR}}}{d t}=k_{c} p_{* \mathrm{PR}}-k^{\prime}{ }_{c} p_{\mathrm{PRO}}
$$

where $k_{e}, k_{c}^{\prime}$ are dependent on the ratio $p_{\mathrm{PRO}} / p_{\mathrm{PR}}-\beta$ and $W$ is the catalyst weight. Introducing the equilibrium condition into Eq. (3), rearranging, integrating and solving for $k_{c}$, one obtains for a flow reactor:

$$
k_{t}=\frac{\dot{V}}{W R T} \frac{1}{1+(1 / \beta)} \ln \frac{1}{1-\alpha},
$$

where $\dot{V}$, is the total volumetric flow rate at room temperature $T$, and $W, R$, are catalyst weight, gas constant, respectively, and $\alpha=p_{* \mathrm{PR} o} /\left(p_{* \mathrm{PR} n}\right)_{e}$ where the suffix $e$ refers to equilibrium conditions.

Values of $k_{c}$ as a function of $\beta$ for the Ag preparations are reported in Fig. 1,

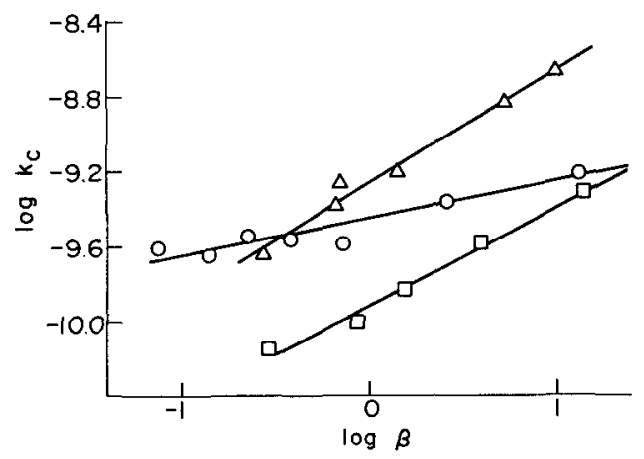

FIg. 2. Values of $\log k_{c}$ [Eq. (4)] versus $\log \beta$ for reaction (1): ( $\odot) \mathrm{Au}-1 \quad\left(270^{\circ} \mathrm{C}\right),(\Delta) \mathrm{Au}-2$ $\left(215^{\circ} \mathrm{C}\right),(\square)\left(\mathrm{VO}_{2}\right)_{x}\left(95^{\circ} \mathrm{C}\right)$.
TABLE 2

VALUES OF $k$ AND $m$ [EQ. (5)] for ReaCtion (1)

\begin{tabular}{lrcc}
\hline Catalyst & $\begin{array}{c}\text { Temp } \\
\left({ }^{\circ} \mathrm{C}\right)\end{array}$ & $m$ & $\begin{array}{c}k \times 10^{\mathbf{1 0}} \\
{[\mathrm{mole} / \mathrm{g}(\mathrm{cat}) \text { sec atm }]}\end{array}$ \\
\hline $\mathrm{Ag}-1$ & 186 & 0.74 & 1.26 \\
$\mathrm{Ag}-3$ & 90 & 0.60 & 1.95 \\
$\mathrm{Ag}-3^{a}$ & 100 & 0.91 & 2.00 \\
$\mathrm{Ag}-5$ & 60 & 0.55 & 8.51 \\
$\mathrm{Au}-1$ & 270 & 0.23 & 5.89 \\
$\mathrm{Au}-2$ & 215 & 0.60 & 5.63 \\
$(\mathrm{VO})_{x}$ & 95 & 0.64 & 1.12 \\
\hline
\end{tabular}

$a$ Reaction (6).

while in Fig. 2 similar results are presented for supported $\mathrm{Au}$ and $\left(\mathrm{VO}_{2}\right)_{x}$.

The experimental results in Figs. 1 and 2 were expressed by the relation

$$
k_{c}=k \beta^{m}
$$

where $k$ is the reaction rate constant. The calculated values of $k$ and $m$ are collected in Table 2. The variation of the value of $m$ with the experimental conditions is consistent with studies $(6)$ on the oxidation of $\mathrm{PR}$ with molecular oxygen on Ag. These investigations showed that with increasing PR partial pressure, the dependence of the rate upon the former decreased from 1 to 0 .

\section{Reaction (2)}

At the temperatures of interest, reaction (2) is favored to take place from left to right. Using standard free energy values, the equilibrium fraction of $\mathrm{PRO}$ in a stoichiometric mixture of PR and ETO was calculated and is reported in Table 3 . No $\mathrm{CO}_{2}$ formation was detected at temperatures $<200^{\circ} \mathrm{C}$. At $220^{\circ} \mathrm{C}$ the amount of

TABLE 3

Equilibrium Fraction $x$ of PRO in A Stoichiometric Mixture of ETO And PR According to Reaction (2)

\begin{tabular}{cc}
$\begin{array}{c}\text { Temp } \\
\left({ }^{\circ} \mathrm{C}\right)\end{array}$ & $x$ \\
\hline 100 & 0.959 \\
150 & 0.918 \\
200 & 0.929 \\
250 & 0.877 \\
\hline
\end{tabular}


TABLE 4

Results on Reaction (2) Catalyzed by Ag-1

\begin{tabular}{|c|c|c|c|c|c|c|c|c|}
\hline \multirow[b]{2}{*}{$\begin{array}{l}\text { Temp } \\
\left({ }^{\circ} \mathrm{C}\right)\end{array}$} & \multicolumn{5}{|c|}{ Feed } & \multicolumn{3}{|c|}{ Products } \\
\hline & $\begin{array}{c}\mathrm{N}_{2} \\
(\mathrm{~atm})\end{array}$ & $\begin{array}{c}\mathrm{PR} \\
(\mathrm{atm})\end{array}$ & $\begin{array}{l}\text { ETO } \\
(\mathrm{atm})\end{array}$ & $\begin{array}{c}\text { Ratio } \\
\text { PR/ETO }\end{array}$ & $\begin{array}{c}\text { ET } \\
(\operatorname{vol} \%)\end{array}$ & $\begin{array}{l}\text { PRO } \\
(\text { vol \%) }\end{array}$ & $\begin{array}{c}\mathrm{CO}_{2} \\
(\operatorname{vol} \%)\end{array}$ & $\begin{array}{c}\text { PRO } \\
{[\text { mole } / \mathrm{g}(\mathrm{cat}) \mathrm{sec}] \times 10^{11}}\end{array}$ \\
\hline \multirow[t]{8}{*}{240} & 0.766 & 0.213 & 0.020 & 10.56 & 0.12 & 0 & 0.43 & 0 \\
\hline & 0.788 & 0.190 & 0.0211 & 8.99 & 0.14 & 0.02 & 0.35 & 0.47 \\
\hline & 0.807 & 0.146 & 0.043 & 3.36 & 0.70 & 0.19 & 1.07 & 5.50 \\
\hline & 0.827 & 0.121 & 0.045 & 2.71 & 0.85 & 0.15 & 2.60 & 3.87 \\
\hline & 0.779 & 0.132 & 0.085 & 1.56 & 0.43 & 0.77 & 0.64 & 25.0 \\
\hline & 0.822 & 0.086 & 0.088 & 0.97 & 0.59 & 0.63 & 0.90 & 16.2 \\
\hline & 0.817 & 0.056 & 0.119 & 0.47 & 0.57 & 1.84 & 1.72 & 49.2 \\
\hline & 0.829 & 0.044 & 0.120 & 0.36 & 0.66 & 1.81 & 1.73 & 45.6 \\
\hline \multirow[t]{9}{*}{220} & 0.774 & 0.176 & 0.047 & 3.75 & 0.10 & 0.34 & 0.99 & 11.2 \\
\hline & 0.832 & 0.114 & 0.049 & 2.35 & 0.16 & 0.36 & 2.28 & 8.77 \\
\hline & 0.763 & 0.159 & 0.075 & 2.13 & 0.14 & 0.16 & 1.08 & 5.58 \\
\hline & 0.804 & 0.120 & 0.072 & 1.66 & 0.18 & 0.20 & 1.47 & 5.73 \\
\hline & 0.814 & 0.109 & 0.073 & 1.48 & 0.21 & 0.26 & 1.56 & 7.20 \\
\hline & 0.690 & 0.134 & 0.171 & 0.79 & 0.49 & 0.93 & 0.04 & 42.0 \\
\hline & 0.799 & 0.072 & 0.123 & 0.58 & 0.32 & 1.59 & 1.58 & 47.0 \\
\hline & 0.811 & 0.061 & 0.118 & 0.51 & 0.32 & 3.01 & 2.32 & 83.8 \\
\hline & 0.734 & 0.075 & 0.186 & 0.40 & 0.58 & 1.27 & 0.29 & 50.0 \\
\hline \multirow{3}{*}{200} & 0.851 & 0.062 & 0.083 & 0.75 & 0.57 & 0 & 2.19 & 0 \\
\hline & 0.848 & 0.059 & 0.085 & 0.69 & 0.56 & 0 & 3.64 & 0 \\
\hline & 0.850 & 0.058 & 0.086 & 0.67 & 0.58 & 0 & 3.61 & 0 \\
\hline
\end{tabular}

$\mathrm{CO}_{2}$ formed was almost independent of the ratio $p_{\mathrm{ETO}} / p_{\mathrm{PR}}$. At higher temperatures, $\mathrm{CO}_{2}$ formation increased with the $p_{\text {ETO }} / p_{\mathrm{PR}}$ ratio. With contact times of about 10 sec, up to 3 vol \% of PRO was measured in the reaction products. A summary of the experimental results is given in Table 4.

\section{Discussion}

The significant conclusions which may be derived from the results of the previous section are: (a) on all catalysts studied the rate of reaction (1) could be quantitatively followed without serious interference from side reactions by choosing conditions of low reaction conversion and temperature; (b) the rate of reaction (1) increased with increasing $\beta$; (c) the values of the exponent $m$ in Eq. (5) were in the range $0.6-0.8$ for all catalysts, except for Au-1. Specifically, Ag catalysts exhibited a value of $m$ higher than that for Au catalysts; the value for $\left(\mathrm{VO}_{2}\right)_{x}$ was intermediate between the two groups; (d) when $\mathrm{ET}$ was substituted to $P R$ in reaction (1) on catalyst $\mathrm{Ag}-3$, the value of $m$ increased from 0.61 to 0.90 ; (e) reaction (2) could be observed on catalyst Ag-1 without serious loss to side products in the temperature range 200 to $240^{\circ} \mathrm{C}$ thus providing a novel route to the epoxidation of $\mathrm{PR}$.

We shall discuss first the results on reaction (1). 'The effects reported are the result of the mixed adsorption of $P R$ and PRO at the catalyst surface under conditions of chemical interaction. The rate of reaction (1) is dependent upon the concentration of surface sites available for $P R$ adsorption. The sites must contain oxygen as evidenced by the fact that the rate increased with $\beta$ [item (b)]. Since PRO is the only form of convertible oxygen present in the system, the surface sites are essentially a form of the adsorbed PRO. The important surface interaction, then, is represented by a specific adsorption of $\mathrm{PR}$ upon a site containing PRO, leading to the formation of PRO. This adsorption is most 
likely single site adsorption. In fact, it is difficult to visualize any other type of adsorption leading uniquely to oxygen transfer between PR and PRO without the concomitant occurrence of side reactions of dehydrogenation, isomerization and decomposition. If this adsorption mode prevails over most of the surface, the concentration of surface sites available for PR adsorption will be $\propto\left(p_{\mathrm{PRO}} / p_{\mathrm{PR}}\right)$ and consequently the rate of reaction (1) will also be $\propto\left(p_{\mathrm{PRO}} / p_{\mathrm{PR}}\right)$. If, however, the adsorption of PR necessitates one pair of adjacent sites per $P R$ molecule (two site adsorption) the rate of reaction (1) will be $\propto\left(p_{\mathrm{PRO}} / p_{\mathrm{PR}}\right)^{1 / 2}$. These are limiting situations. There are, of course, possibilities of intermediate behavior in which both adsorption modes play a role. Inspection of Table 2 shows that on all catalysts studied there is evidence of intermediate behavior and more complex conditions. However, trends are discernible. For catalysts Ag-3, Ag-5, Au-2 and $\left(\mathrm{VO}_{2}\right)_{x} m \approx$ 0.60 , suggesting that on the surfaces of these catalysts two site adsorption was predominant. Catalyst Ag-1 revealed an increased tendency towards one site adsorption. On catalyst Ag-3 the value of $m$ increased from 0.61 to 0.91 when the carbon isotope exchange reaction was performed between ${ }^{*} \mathrm{ET}$ and PRO (Fig. 3), namely:

$$
{ }^{*} \mathrm{ET}(\mathrm{g})+\mathrm{PRO}(\mathrm{g}) \rightarrow \mathrm{ET}(\mathrm{g})+{ }^{*} \mathrm{PRO}(\mathrm{g}) .
$$

Although this is a more complex exchange

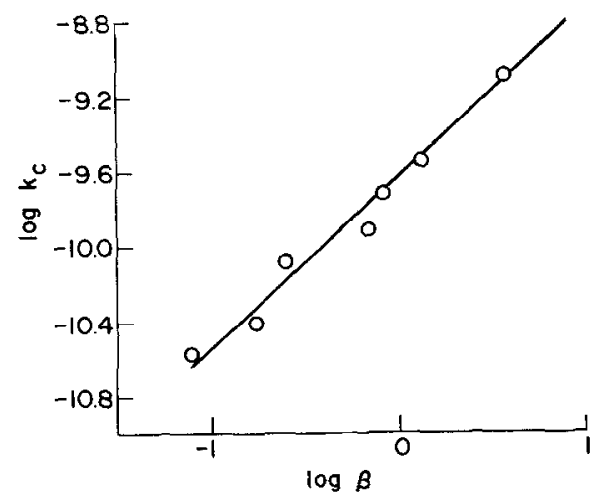

Fig. 3. Values of $\log k_{c}$ versus $\log \beta^{\prime}$ for reaction (6); $\left[\beta^{\prime}=P_{\mathrm{C}_{3} \mathrm{H}_{0 \mathrm{O}}} / P_{\mathrm{C}_{3} \mathrm{H}_{4}}\right]$; catalyst $\mathrm{Ag}-3$, $100^{\circ} \mathrm{C}$. reaction, its surface pathway must include ET adsorption upon an oxygenaled site. This suggests that single site adsorption occurs more frequently with ET rather than PR. This conclusion is corroborated by comparing values of $m$ reported in Table 2 , with those obtained previously from measurements on the rate of the carbon isotope exchange between ET and ETO (1), namely,

$$
* \mathrm{ET}(\mathrm{g})+\mathrm{ETO}(\mathrm{g}) \rightarrow \mathrm{ET}(\mathrm{g})+{ }^{*} \mathrm{ETO}(\mathrm{g}) .
$$

With the exception of catalyst Au-1, the values of $m$ for reaction (7) were similar or higher than those reported in Table 2. Since single site nondissociative adsorption of the olefin seems to be a prerequisite for the formation of a high concentration of adsorbate leading to intermediate oxidation products (PRO, acrolein), the discussion on the values of the exponent $m$ suggests that catalyst $\mathrm{Ag}-1$ should reveal in the presence of $\mathrm{PR}$ and molecular oxygen a higher selectivity to intermediate oxidation products. This is a tentative conclusion since the role of the adsorption of oxygen in the control of the reaction pathway for the catalysts studied has not yet been assessed.

The rate constants reported in Table 2 are of the same order of magnitude $\{\sim(1$ to 10$) \times 10^{-10}[\mathrm{~mole} / \mathrm{g}(\mathrm{cat}) \mathrm{sec}$ atm $\left.]\right\}$ as those previously reported for the adsorption of ET-ETO mixtures (1). The latter results may be combined with the present ones in the following way. According to reasoning presented in the previous section for reaction (1), it may be assumed that reaction (7) is the resull of a similar two step adsorption-desorption sequence, namely:

$$
\begin{aligned}
{ }^{*} \mathrm{ET}(\mathrm{g})+\mathrm{O}(\mathrm{s}) & \rightarrow{ }^{*} \mathrm{ETO}(\mathrm{g}), \\
\operatorname{ETO}(\mathrm{g}) & \rightarrow \mathrm{ET}(\mathrm{g})+\mathrm{O}(\mathrm{s}) .
\end{aligned}
$$

Consequently, the experimentally observed rate of reaction ( 7 ) gives directly the rate of ETO adsorption (step 7b). Previous results on reaction (7b) on catalyst Ag-1, $174^{\circ} \mathrm{C}$, have been recalculated using the equation $k_{c}=\{\dot{V} /[W R T(1+\beta)]\}$ $\ln (1 / \alpha)$ to give the rate of reaction step 


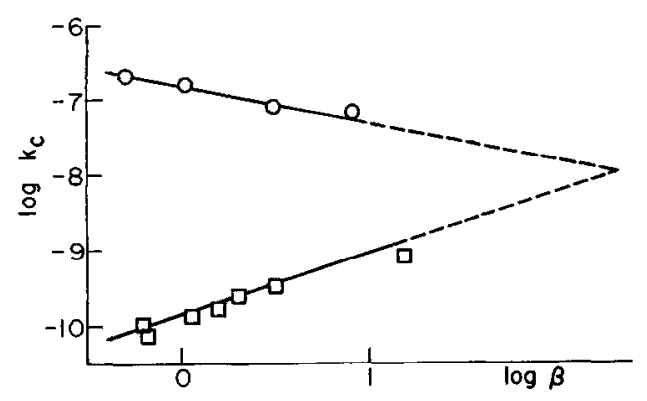

FIg. 4. $\log k_{c}$ versus $\beta$ : reaction $(1), 186^{\circ} \mathrm{C}$, ( $\square$ ) reaction (7), $171^{\circ} \mathrm{C}$ (@) $\mathrm{Ag-1} ; \beta=P_{\mathrm{PRO} /}$ $P_{\mathrm{PR}}$ for reaction (1), $\beta=P_{\mathrm{ETO}} / P_{\mathrm{ET}}$ for reaction (7).

(7b) as a function of the ratio $p_{\text {ETO }} / p_{\text {ET }}$. The results are plotted in Fig. 4 together with those obtained during this investigation on catalyst $\mathrm{Ag}-1$ at $174^{\circ} \mathrm{C}$. Neglecting the temperature difference between the two sets of results, a linear extrapolation to a similar $k_{c}$ for both reactions, gives a value of $k_{c} \approx 1 \times 10^{-8}$ [mole $/ \mathrm{g}$ (cat) sec atm] at $\beta \cong 160$. There is no direct way to assess a priori the validity of the linear extrapolation since it rests on the behavior of the adsorption isotherm of the mixed system in the region of high $\beta$. A similar comparison and extrapolation of the results on reactions (1) and (7) were carried out for catalyst $\mathrm{Ag}-5$ at $65^{\circ} \mathrm{C}$ (Fig. 5). In this instance a similar value of $k_{c}$ for the two reactions is found at $\beta \cong 310$.

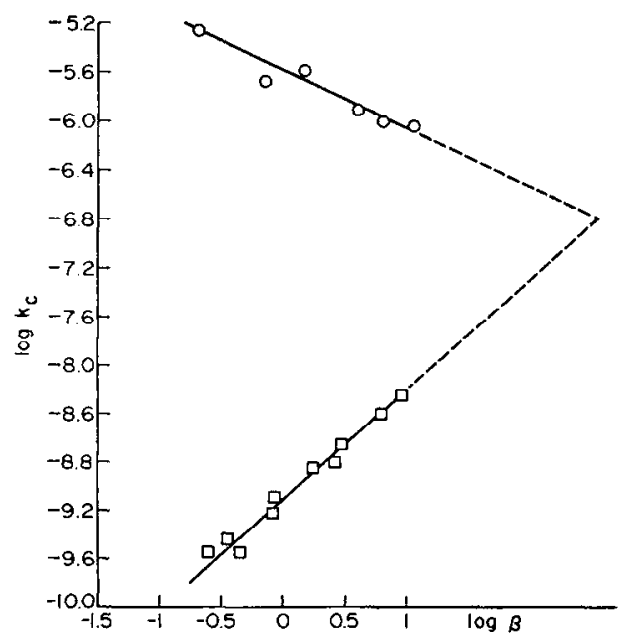

FIG. 5. Log $k_{c}$ versus $\beta$ : reaction (1) (口) reaction (7) ( $\odot) \mathrm{Ag}-5,65^{\circ} \mathrm{C} ; \beta=P_{\mathrm{PRO}} / P_{\mathrm{PR}}$ for reaction (1), $\beta=P_{\mathrm{ETO}} / P_{\mathrm{ET}}$ for reaction (7).
The combination of reaction steps (1a) and (7b) yields reaction (2). Therefore, the rate of the latter may be estimated from a knowledge of the rates of reaction steps (1a) and (7b). During the steady state of reaction (2): $k_{c}$ [reaction (1a)] $=k_{c}[$ reaction $(7 \mathrm{~b})]=\{v[$ reaction $(1)] /$ $\left.p_{\mathrm{PR}}\right\}=\left\{v[\right.$ reaction $\left.(7)] / p_{\text {ETo }}\right\}$, where $v[$ reaction (1)], $v$ [reaction (7)] are the rates of reactions (1) and (7), respectively.

Since in the reported experiments $p_{\mathrm{PR}}$ and $p_{\text {ETO }}$ were of the order of $0.5 \mathrm{~atm}$, it is possible to predict a rate for reaction (2) of $\approx 10^{-8}$ [moles $\mathrm{PRO} / \mathrm{g}$ cat sec] on catalyst $\mathrm{Ag}-1$ at temperatures 174 to $186^{\circ} \mathrm{C}$ and partial pressure ratios $\mathrm{p}_{\mathrm{ETO}} / p_{\mathrm{ET}} \approx p_{\mathrm{PRO} /}$ $p_{\mathrm{PR}}=160$. In this estimate kinetic isotope effects in reactions (1a) and (7b) have been neglected. To verify this prediction, the results reported in Table 3 may be helpful. Assuming that the influence of the ratio $p_{\mathrm{ETO}} / p_{\mathrm{PR}}$ on the rate of reaction (2) is similar to that of the ratios $p_{\text {ЕTO }} / p_{\text {ET }}$ and $p_{\mathrm{PRO}} / p_{\mathrm{PR}}$ on reaction steps $(7 \mathrm{~b})$ and (1a), respectively, and using the experimental results at $200^{\circ} \mathrm{C}$ it is possible to derive a rate of $\approx 4 \times 10^{-8}$ catalyst $\mathrm{Ag}-1$ [mole $\mathrm{PRO} / \mathrm{g}$ cat sec] at $\beta=160$. Although this is a crude estimate, it is nonetheless within an order of magnitude of the predicted value, giving support to the kinetic scheme (1a) (7b) for reaction (2). It is also noteworthy that the results of Table 3 reveal that the amount of PRO formed increased, with the ratio $p_{\mathrm{ETO}} / p_{P R}$. This is consistent with the reaction scheme (1a) and (7b). It is not possible to compare directly the present results with those on the catalytic oxidation of $P R$ by molecular oxygen, since the details of the adsorption of oxygen in the presence of PR and the relative rates of the lwo adsorption steps of propylene and oxygen taking place simultaneously at the same catalytic surface are not known.

\section{Conclusrons}

Conceivably single site adsorption of propylene is the characteristic pathway to PRO. In fact it is possible to argue that the formation of acrolein in the oxidative dehydrogenation with the concomitant formation of a secondary product $\left(\mathrm{H}_{2} \mathrm{O}\right)$ is a 
more complex sequence of surface steps. This may require more than one site attachment of the olefin or a rapid rearrangement of the adsorbate. In this light the present results may be significant for the direct epoxidation of propylene. Although definitive predictions cannot be made for lack of a direct measurement of catalyst selectivity, the results may be helpful in setting relative rankings of catalyst selectivity in terms of the nature of the reactive adsorption of propylene. This confidence is further justified by the internal consistence of the reaction scheme discussed; namely, the direct occurrence of reaction (2) whose rate was within one order of magnitude from that predicted from the study on reaction (1).

\section{ACKNOWLEDGMENT}

One of us (G.M.) thanks the management of SNAM Progetti S.p.A. for financial support which made this work possible. Financial assistance from the National Science Foundation through Grant GK-2013 is gratefully acknowledged.

\section{REFERENCES}

1. Manara, G., and Parrayano, G., J. Catal. 23, 379 (1971).

2. Belusov, V. M., Gorokhovatskil, Y. B., Rubanik, M. Y., and Gershingorina, A. V., Dokl. Akad. Nauk SSSR 132, 1125 (1960).

3. Latyshev, V. P., Kaliberdo, L. M., and Popova, N. I., Kinet. Katal. 6, 167 (1965).

4. Voge, H. H., Wagner, C. D., Stevenson, D. P., J. Catal. 2, 58 (1963); ADAMs, C. R., JENNings, T. J., J. Catal., 2, 63 (1963); SACHTLER, W. M. H., De Botr, H. H., Proc. Int. Congr. Catal. 1, 252 (1964); SACHTLER, W. M. II., Catal. Rev. 4, 27 (1970).

5. Cha, D. Y., and Parravano, G., J. Catal. 18, 200 (1970).

6. VaAbel, A. S., Kubakina, P. R., and Kaliberdo, L. M., Kinet. Katal. 9, 868 (1968). 